\title{
DENGUE FEVER;
}

THE CLINICAL PATTERN AND MORTALITY IN EPIDEMIC AND POST EPIDEMIC YEARS IN SWAT

1. FCPS

Assistant Professor

Department of Medicine,

Saidu Medical College, Swat.

2. FCPS

Associate Professor of Medicine Department of Medicine, Saidu Medical College, Swat

3. FCPS

Assistant Professor of Surgery, King Abdullah Teaching Hospital, Mansehra.

4. FCPS

Consultant Accident and

Emergency Department

Ayub Teaching Hospital,

Abbottabad.

5. FCPS

Professor of Surgery,

Frontier Medical College

Abbottabad.

6. FCPS, MCPS-HPE

Professor of Surgery,

Gajju Khan Medical College,

Swabi.

Correspondence Address:

Dr. Ishtiaq Ali Khan

Professor of Surgery,

Gajju Khan Medical College,

Swabi.

drishtiaq71@yahoo.com

Article received on:

24/03/2017

Accepted for publication:

15/08/2017

Received after proof reading: 06/10/2017
Wasil Khan', Bacha Amin Khan², Zar Khan ${ }^{3}$, Abid ur Rehman, Mohammad Akbar, Ishtiaq Ali Khan ${ }^{6}$

ABSTRACT... Introduction: Dengue fever is arboviral infection transmitted from infected person to non-infected one by mosquitoes Aedes Aegypti or Aedes albopectis. All four serotypes (DEN1, DEN-2, DEN-3 \& DEN-4) can cause the clinical manifestations of disease. Dengue infection can cause acute febrile illness, dengue hemorrhagic fever (DHF) and dengue shock syndrome (DSS). About 50-100 million cases of dengue fever reported annually worldwide in which 0.5 million may need admission. Overall mortality of dengue fever is $3 \%$. The diagnosis of dengue is established by classical clinical features along with specific investigations like PCR, detection of dengue NS1 antigen or IgM or IgG antibodies in the blood of infected person. Dengue is endemic in most part of our country and can become epidemics on and off. Objectives: To study the pattern and mortality of Dengue fever during epidemic and post epidemic years in Swat. Setting: This study was conducted in Medical Department of Saidu Group of Teaching Hospital, Swat. Period: Aug 2013 to November, 2016. Patients and method: Patients suffering from acute febrile illness with features suggestive of Dengue fever were included in the study. Clinical criteria for initial diagnosis directed the subsequent diagnostic work up. Dengue was confirmed in these patients by either Dengue NS1 or Ig M antibodies in their blood. Written consent for participation in study was taken from all the included patients. Formal permission was taken from Institutional Review Board of the institution to perform this study. The clinical and laboratory data were recorded on a proforma and analyzed using SPSS 20. Results: Among 5569 patients, 3834 (68.85\%) were male and 1735 (31.15\%) were female. The mean age of the patients was 30 years SD 15.20. The most common age group that suffered with Dengue fever was the adult age group (13-30 years). Dengue Hemorrhegic Fever was diagnosed in $2543(45.6 \%)$ patients and $50(0.89 \%)$ had features of DSS. A total $5018(90.1 \%)$ patients were completely cured while $37(0.66 \%)$ patients died. The overall mortality was $0.66 \%$. Patients with Dengue fever presented to the hospital though out the year but more than $50 \%$ of cases were reported in the month of September. Conclusion: Adult age group and male gender is most commonly affected by Dengue fever. Dengue fever was endemic in Swat valley and it can become cyclic epidemic in post epidemic years. Dengue fever can claim so many precious lives if proper preventive measures were not taken in future.

Key words: $\quad$ Dengue Fever, Dengue Hemorrhagic Fever, Dengue Shocks Syndrome.

Article Citation: Khan W, Khan BA, Khan Z, Abid ur Rehman, Akbar M, Khan IA. Dengue fever; the clinical pattern and mortality in epidemic and post epidemic years in Swat. Professional Med J 2017;24(10):1466-1470. DOI:10.17957/TPMJ/17.3947

\section{INTRODUCTION}

Dengue is recognized as one of the increasingly emerging infection of world. Almost 50-100 million cases of dengue fever are reported annually word wide. ${ }^{1}$ In Pakistan first epidemic dengue fever was reported in 1994 at Karachi. ${ }^{2}$ Dengue virus is now endemic in Pakistan, circulating throughout the years with a peak incidence in the post moon soon period. ${ }^{3}$ Ades Egypti or Ades Albopectus, is the mosquitoes responsible for the transmission of dengue fever from an infected person to a healthy one. It is primarily a daytime feeder which lives around human habitat. The favorite breeding places of the mosquitoes are barrels, drum, canes, pots, buckets, flower races, plant sources, tanks, discarded bottles/canes, tiles, water coolers and places where rain water collects. ${ }^{4}$ The causative virus is one of the four different serotypes (DEN-1, DEN-2, DEN-3 \& DEN-4). The incubation period of gangue fever is $2-8$ days. ${ }^{5}$

The clinical features of dengue infection vary 
according to the age of patients. The infant and young children can have only non-specific acute febrile illness with or without rash. The older children and adult one can have a mild classical illness of dengue fever with abrupt onset of high grade fever, severe headache (ret orbital headache) muscle $\&$ joint pain and rash. ${ }^{3}$ Some of the patients with dengue infection can have dengue hemorrhagic fever (DHF) or even dengue shock syndrome (DSS). The risk of sever disease like DHF and DSS is higher in sequential rather than primary infection. ${ }^{6}$

Epidemic potential of dengue fever depends on viremia level, infectivity and serotype of the virus. DHF risk is greater for DEN-2 followed by DEN3. ${ }^{7}$ According to a study by NIH ISLAMABAD, all four serotypes of dengue virus are circulating in Khyber Pakhtunkhwa but the most common serotypes were DEN- 2 \& DEN-3. ${ }^{8}$

Diagnosis of dengue fever or its complication needs culture of virus, detection of viral DNA with PCR or by serology. Low white blood cell count, low platelets count, deranged liver function test (LFT), IgM and IgG antibodies level for the detection of disease are other important tests. ${ }^{9}$ Primary dengue fever needs only supportive treatment but dengue with complications like DHF and DSS needs intensive cares. ${ }^{10}$

In previous 2-3 years, dengue was endemic in lush valley of Swat, but from 2013 it appeared in epidemic form. ${ }^{11}$

The aim of this study is to know the pattern and mortality of dengue fever in Swat valley and adjacent areas.

\section{PATIENTS AND METHODS}

This descriptive case series was conducted in Department of Medicine, Saidu Group of Teaching Hospital Swat from Aug 2013 to November 2016.

All patients of acute febrile illness with classical features of dengue were included in the study. Dengue fever (DF) was defined as fever with or without rash, rets orbital headache, conjunctival congestion and myalgia. Dengue hemorrhagic fever (DHF) was characterized by a triade of hemorrhagic manifestations; platelets count less than 100,000 and clinical signs of plasma leakage in the form of plural effusion, ascites or raised hematocrit. Dengue shock syndrome (DSS) was defined with features of shock in the form of rapid weak pulse and hypotension with systolic blood pressure less than $90 \mathrm{mmHg}$. Platelets count was done by SymexKX-21 and thrombocytopenia was also confirmed by peripheral blood smear.

Baseline investigations of all patients were sent to the hospital main laboratory. The diagnosis of dengue was confirmed by either detection of dengue NS1 antigen or IgM antibodies in the blood of patients depending on the duration of illness.

In some cases, where other complication were suspected, abdominal ultrasound, LFTs, ECG, echo renal function were also advised. Those patients who need intensive care were shifted to HDU/ICU. Ten samples of blood were taken and sent to $\mathrm{NIH}$, Islamabad for PCR detection.

Patients who presented with acute febrile illness and evidence of Dengue fever were included in the study. Patients, who presented with acute febrile illness but were having evidence of other diseases like malaria, typhoid, urinary tract infection, respiratory tract infection and meningitis were excluded from the study.

Informed consent was taken from patients and Institution Review Board to conduct this study. All information, clinical findings and investigations of patients were recorded on a structured proforma and were analyzed using SPSS 20.

\section{RESULTS}

A total 5569 patients were included. Dengue fever was confirmed in 4177 (75\%) by dengue NS1 and $1392(25 \%)$ by $\lg$ M. Out of 5569 patients, 3834 (68.85\%) were male and 1735 (31.15\%) were female. The mean age of the patients was 30 years with SD 15.20 with standard error of 0.20 . Age distribution of patients is shown in Table-I. Maximum number of patients (54.48\%) 
presented in month of September as shown in Figure-1. Most of the patients (93.4\%) presented to the hospital during 2013 as depicted in TableII. Three hundred and fifty one (6.3\%) patients needed intensive care and were shifted to intensive care unit. Dengue hemorrhagic fever was diagnosed in 2543 (45.6\%) patients and $50(0.89 \%)$ had features of DSS. Among 5569 patients, $5018(90.1 \%)$ patients were completely cured and $37(0.66 \%)$ patients died in which 35 $(94.59 \%)$ had other serious comorbidities like uncontrolled diabetes mellitus, chronic kidney disease, congestive cardiac failure, stage four malignancies, acute severe asthma. The platelets counts of only $3021(54.25 \%)$ patients were more than $100000 / \mathrm{cm}$ as shown in Table-III. All these patients with thrombocytopenia did not develop bleeding and were managed with normal saline or dextran 40. Only two of them needed platelet transfusion.

\begin{tabular}{|c|c|c|}
\hline Sr. No. & Age in years & No of patients $(\%)$ \\
\hline 1 & $1-13$ & $500(8.97)$ \\
\hline 2 & $14-30$ & $2935(52.71)$ \\
\hline 3 & $31-60$ & $1927(34.61)$ \\
\hline 4 & $>61$ & $207(3.71)$ \\
\hline & Total & $5569(100)$ \\
\hline & Table-l. Age distribution $(n=5569)$ \\
\hline
\end{tabular}

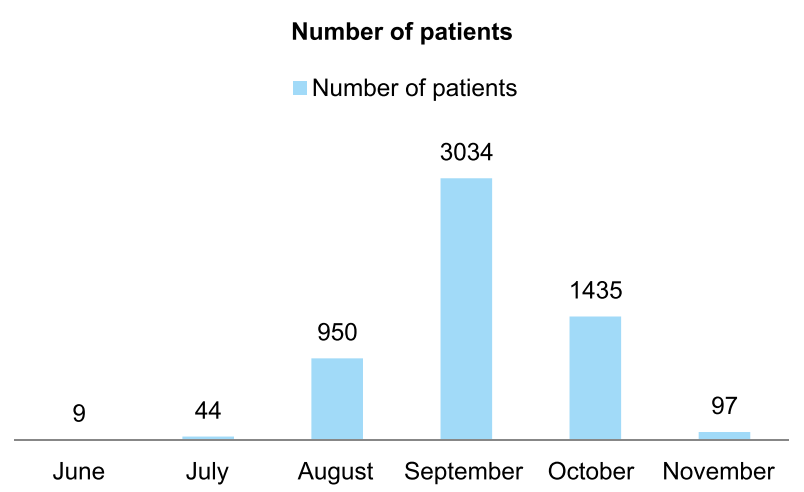

Figure-1. Frequency of presentation of patients during different months

\begin{tabular}{|c|c|c|}
\hline Sr. No. & Year & Number of patients (\%) \\
\hline 1 & 2013 & $5201(93.4)$ \\
\hline 2 & 2014 & $290(5.2)$ \\
\hline 3 & 2015 & $33(0.6)$ \\
\hline 4 & 2016 & $45(0.8)$ \\
\hline \multicolumn{3}{|c|}{ Total } \\
\hline
\end{tabular}

Table-II. Yearly distribution of patients' presentation

\begin{tabular}{|c|l|c|}
\hline Sr. No. & $\begin{array}{c}\text { Range of platelet } \\
\text { count }\end{array}$ & $\begin{array}{c}\text { Number of patients } \\
\text { (\%) }\end{array}$ \\
\hline 1 & $>100000 / \mathrm{C} \mathrm{mm}$ & $3021(54.25)$ \\
\hline 2 & \begin{tabular}{l}
99999 to $50000 / \mathrm{C} \mathrm{mm}$ \\
\hline 3
\end{tabular} & $\begin{array}{l}<50000 \text { to } 200000 / \\
\mathrm{C} \mathrm{mm}\end{array}$ \\
\hline 4 & $<20000$ & $681(12.23)$ \\
\hline & Total & $159(2.85)$ \\
\hline Table-III. Platelet count of patients with dengue fever
\end{tabular}

\section{DISCUSSION}

The endemic of dengue fever is spreading with rapid expansion of population to new area like from urban to rural one. A severe dengue outbreak appeared in the province of Punjab which badly hit Lahore in 2011 and claimed 290 deaths. ${ }^{12}$ Swat, a lush green valley of 1.3 million population remained under militant insurgency from 2007 to 2009. Before 2010, dengue infection was a rare phenomenon observed in the valley. An outbreak of dengue fever was experienced in the month of August in 2013 and extended to November 2013. More than 16000 suspected patients who were having acute febrile illness screened for dengue fever. Among them, 5569 were confirmed as dengue fever. Dengue NS1 was found in 4177 (75\%) and 1392 (25\%) were detected by dengue $\operatorname{lgM}$ anti-bodies. NS1 antigen is abundant in the serum of inpatient during early stages of disease (0-9 days). It is directly correlated with viremia and is an easy, fast and feasible alternative to PCR in developing countries with simple laboratory set up. ${ }^{13}$ Dengue IgM anti-bodies start appearing in the blood by 4 to 5 days and peak at two week time. It shows cross reactivity with other flavi virus infection and can give false positive results. ${ }^{14}$ False negative IgM reaction can be observed during secondary infection. ${ }^{15}$ Despite of this, IgM has high specificity and sensitivity and remains stable at tropical room temperature.$^{16}$ In endemic areas like Swat, it is the IgM anti-body detection rather NS1 Ag which has clinched the diagnosis of dengue fever. ${ }^{17}$ Therefore we used both NS1 $\mathrm{Ag}$ and $\operatorname{lgM}$ anti-bodies for the confirmation of dengue. For more accuracy we recorded the day of onset of fever for every patient in our study so we can decide for NS1 Ag or IgM antibodies to be ordered. We have found that dengue was more prevalent in males; the ratio male to female 
was (2.2:1). This pattern has been also observed by Garg et al and other workers. ${ }^{15,18}$ This male predominance is due to the more chances of exposure of male patient to vector in the form of outdoor activities. Though Dengue fever was found in all age groups but the 13 to 30 years old age was more affected than the others. Similar age pattern was reported from India, Myanmar, Karachi and Lahore. ${ }^{19,20,21,22,23}$ Unlike the observation of Garg et al., the least number of children were affected by Dengue fever in our study (1\%). ${ }^{18}$ For seasonal variation, month wise data was analyzed and it was observed that majority of cases were reported during month of September, which is a post monsoon period in the valley. Such pattern of seasonal variation of the disease was reported by other observers as well. This is due to the favorable temperature and humidity condition in which the vector (mosquito) breeds well. ${ }^{18,23,19,21,25}$ The overall mortality in our patients was 0.66 percent and it is a bit higher than the mortality of 0.4 percent as reported by Choudhry $\mathrm{M}$, et al in their study. ${ }^{11}$ But our mortality $(0.66 \%)$ is very low than the mortality of Lahore epidemic (3\%) that occurred in of $2011 .{ }^{26}$ We have also observed that frequency of DHF patients has increased from $45.6 \%$ during epidemics of 2013 and post-epidemic years 2014-15 to $70 \%$ in 2016 . Though the patients were having DHF in 2016 were not aware of illness in previous years but they can have asymptomatic illness and now it has been presumed that they were having secondary rather than primary dengue infection. This confirmed the view that risk of severe disease is much higher in sequential rather primary dengue infection. ${ }^{6}$

\section{Limitations of the study}

This study included only those patients who were either referred to Saidu Group of Teaching Hospital, Swat or they visited on their own to outpatient department. It does not include those patients of swat valley who were treated outside or referred to other hospital of the province or country.

\section{CONCLUSION}

The dengue fever, which was endemic in swat valley, can become cyclic epidemic in post epidemic years, if proper preventive measures were not taken in future, the sequential infection again can claim so many lives.

Copyright(c) 15 Aug, 2017.

\section{REFERENCES}

1. Dengue Fever World Health Organization Fact Sheet No.117. 2009.

2. Jawad K A, Masood S, Tassawar H, Inam B, Waheeduz ZT. Outbreak of Dengue Hemorrhagic Fever in Karachi. Pak Armed Forces Med J 2001; 51(2):94-8.

3. Naseem S, Farheen A, Muhammad A, Fauzia R. Dengue fever outbreak in Karachi, 2005--A clinical experience. Infect Dis J 2005; 14(4):115-7.

4. Gibbons RV, Vaughn DW. Dengue: an escalating problem. BMJ 2002; 324: 1563-1566.

5. Guzman MG, Kouri G. Dengue: an update. Lancet Infect Dis 2002; 2:33-42.

6. Guzman, M.G., Alvarez, M. \& Halstead, S.B. Secondary infection as a risk factor for dengue hemorrhagic fever/dengue shock syndrome: an historical perspective and role of antibody-dependent enhancement of infection. Arch Virol 2013; 158: 1445.

7. Almas A, Parkash $O$, Akhter J. Clinical factors associated with mortality in dengue infection at a tertiary care centre. Southeast Asian J Trop Med Public Health 2010; 41(2):333-40.

8. Humayoun MA, Waseem T, Jawa AA, Hashmi MS, Akram $J$. Multiple dengue serotypes and high frequency of dengue hemorrhagic fever at two tertiary care hospitals in Lahore during the 2008 dengue virus outbreak in Punjab, Pakistan. Int J Infect Dis. 2010; 14S3:e54-e59. doi: 10.1016/j.ijid.2009.10.008.

9. Suleman M, Faryal R, Alam MM, SharifS, ShaukatS, Aamir UB, Khurshid A, Angez M, Umair M, Sufian MM, Arshad Y, Zaidi SS. Dengue Virus Serotypes Circulating in Khyber Pakhtunkhwa Province, Pakistan, 2013-2015. Ann Lab Med 2017; 37(2):151-154.

10. Butt N, Abbassi A, Munir SM, Ahmad SM, Sheikh QH. Haematological and biochemical indicators for the early diagnosis of dengue viral infection. $J$ Coll Physicians Surg Pak 2008; 18(5):282-5.

11. Muhammad A, Adel MK, Eman HL, Shahid B, Adnaan YA, Sawsan AU. Characteristics of Dengue Fever in a large public hospital, Jeddah, Saudi Arabia. J Ayub Med Coll Abottabad 2006; 18(2):9-13.

12. Chaudhry M, Ahmad S, Rashid HB, Din IU. Dengue epidemic in postconflict swat district, Khyber Pakhtunkhwa, Pakistan, 2013. Am T Trop Med Hyg. 
2017 jan 16 pii: 16-0608.

13. Rafique I, Nadeem Saqib MA, Munir MA, Qureshi $H$, Siddiqui S, Habibullah S, Bashir S, Rehman S, Ashraf $S$ Economic burden of dengue in four major cities of Pakistan during 2011. J Pak Med Assoc 2015 Mar; 65(3):256-9.

14. Solanke VN, Karmarkar MG, Mehta PR. Early dengue diagnosis: Role of rapid NS1 antigen, NS1 early ELISA, and PCR assay. Tropical J Medical Research 2015; 18: 95-99.

15. Bilal H, Hassan SA, Khan IA. Isolation and efficacy of entomopathogenic fungus (Metarhizium anisoude) for the control of Aedes albopictus Skuse larvae: suspected dengue vector in Pakistan. Asian Pac J Trop Biomed 2012; 2: 298-300.

16. World Health Organization. Neglected tropical diseases. WHO press; 2016; Available from www.who. int/neglected-diseases/disease/en/2016.

17. Mishra B, Gupta PK, Dhiman V, Pujhari SK, Sharma M, Ratho RK. Clinical Applicability of various dengue diagnostic tests in resource-limited endemic settings. J Glob Infect Dis 2014; 6: 109-13.

18. Singla N, Kaur P, Chander J. Evaluation of NS1Ag and IgM antibodies against dengue, [18] importance for epidemiological surveillance. Asian Pac $\mathrm{J}$ Trop Dis 2013; 251-52.

19. Garg A, Garg J, Rao YK, Upadhyay GC, Sakhuja S. Prevalence of dengue among clinically suspected febrile episodes at a teaching hospital in North India. $\mathrm{J}$ Infect Dis Immun 2011; 3:85-89.

20. Neeraja M, Lakshmi V, Dash PK, Parida MM, Rao PVL. The clinical, serological and molecular diagnosis of emerging dengue Infection at a tertiary care institute in Southern, India. Journal of Clinical and Diagnostic Research 2013; 7: 457-461.

21. Khan SA, Dutta P, Borah J, Chowdhury P, Doloi PK, Mahanta J. Dengue outbreak in an Indo-Myanmar boarder area: epidemiological aspects and risk factors. Trop Biomed 2013; 30: 451-58.

22. Akula S, Kammili N. Serological and virological profile of dengue fever in a tertiary care hospital, southern part of Hyderabad, during 2011-12. Int $\mathrm{J}$ Microbiol 2015; $1: 1-7$.

23. Mishra B, Gupta PK, Dhiman V, Pujhari SK, Sharma M, Ratho RK. Clinical Applicability of various dengue diagnostic tests in resource-limited endemic settings. J Glob Infect Dis 2014; 6: 109-13.

24. Kariyawasam S, Senanayake H. Dengue infections during pregnancy: case series from a tertiary care hospital in Sri Lanka. J Infect Dev Ctries 2010; 4: 76775.

25. Bhattacharya MK, Maitra S, Ganguly A, Bhattacharya A, Sinha A. Dengue: A growing menace - A snapshot of recent facts, figures \& remedies. Int J Biomed Sci 2013; 9: 61-67.

26. Paramasivan R, Thenmozhi V, Thangaratham PS, Rajendran R, Tewari SC, Dhananjeyan KJ, et al. An outbreak of dengue fever in Tirupur, Coimbatore district, Tamil Nadu. Indian J Med Res 2010; 132: 10507 .

27. Ahmed S, Mohammad WW, Hamid F, Akhter A, Afzal RK, Mahmood A. The 2011 dengue haemorrhagic fever outbreak in Lahore - an account of clinical parameters and pattern of haemorrhagic complications. J Coll Physicians Surg Pak 2013 Jul; 23(7):463-7.

\section{AUTHORSHIP AND CONTRIBUTION DECLARATION}

\begin{tabular}{|c|l|l|}
\hline Sr. \# & Author-s Full Name & \multicolumn{1}{|c|}{ Contribution to the paper } \\
\hline 1 & Wasil Khan & $\begin{array}{l}\text { Conceive idea, Critical revision, Final } \\
\text { approval. } \\
\text { Designed methodology, Acquisition } \\
\text { of data, Drafting, Final approval. } \\
\text { Conceive idea, Drafting, Final } \\
\text { approval. }\end{array}$ \\
\hline 5 & Bacha Amin Khan & Zar Khan \\
4 & Abid ur Rehman & $\begin{array}{l}\text { Analysis of data, Drafting the } \\
\text { manuscript, Final approval. } \\
\text { Interpretation of data, Critical revision, }\end{array}$ \\
6 & Ishtiaq Ali Khan & $\begin{array}{l}\text { Final approval. } \\
\text { Conceive idea, Critical revision, Final } \\
\text { approval. }\end{array}$ \\
\hline
\end{tabular}

